\title{
CAZUMBÁ: NOMES E RASTROS
}

\author{
Maria Cristina Machado de Carvalho ${ }^{1}$
}

\section{Resumo}

Este trabalho parte de uma pesquisa maior dedicada as experiências de indivíduos e de grupos familiares na condição de cor em Feira de Santana e no Recôncavo da Bahia no século XIX. Destarte, este artigo trata sobre a origem do nome e a sua experiência da família Cazumbá, o que permitiu compreender as trajetórias de vida, a relação entre escravos e livres, o acesso à terra, a tradição e o significado da liberdade atribuído por aqueles viveram a escravidão, ou então, descenderam deles. Desses movimentos notar-se que a terra foi importante componente de sobrevivência ligada aos diferentes significados de liberdade.

\footnotetext{
1 Doutoranda em História Social UFRRJ.
} 


\section{Introdução}

"Escritura de venda, compra, paga e quitação que faz o Major Francisco Antônio de Carvalho, da fazenda antigamente denominada Várzea e hoje sobrado, pela, digo [ilegível]das terras, casas e benfeitorias da fazenda antigamente denominada Várzea, hoje sobrado, pela quantia de um conto oitocentos mil réis, a Manoel Ferreira de Cerqueira e João Cardozo Cazumbá, como abaixo declara.

Saibam quantos este instrumento e escritura de venda, compra, paga e quitação, virem, que sendo o ano do nascimento de Nosso Senhor Jesus Cristo de mil oitocentos e setenta e nove, aos trinta dias do mês de junho do dito ano, neste arraial da freguesia de São Gonçalo dos Campos, termo da cidade da Cachoeira, em meu cartório compareceram presentes partes justas e contratadas, de uma como vendedor, o Major Francisco Antônio de Carvalho, morador da cidade de Santo Amaro, e de outra, como compradores Manoel Ferreira de Cerqueira e João Cardozo Cazumbá, moradores desta freguesia, e bem conhecidos de mim escrivão de paz interinamente juramentado, no impedimento do atual, do que dou fé. E logo pelo referido vendedor me foi dito em presença das testemunhas no fim declaradas e designadas, que era senhor e legítimo possuidor das terras, casa e benfeitorias da fazenda antigamente denominada Várzea e hoje Sobrado, cuja fazenda the foi adjudicada pelo juiz de órfãos da cidade de Santo Amaro, Joaquim, digo, Amaro, Joqquim [ilegível] de Almeida Freitas, por parte dos menores do finado comendador Antônio Lopes Ferreira e Souza, que era seu devedor, e a quem pertencia a referida fazenda acima declarada, cujas terras se divide da maneira seguinte; pelo lado sul com terras que ficaram de João da Maya Machado, pelo este com terras que ficaram do padre Gonçalo de Souza, e pelo leste e norte, com terras de Estevão Machado, tudo por baixas e estradas, cujas terras assim demarcadas, e divididas, casa, e benfeitorias, vende e vendido tinha de hoje em diante aos senhores Manoel Ferreira de Cerqueira e João Cardozo Cazumbá, pela quantia de um conto e oitocentos mil réis, cuja quantia recebia ao fazer desta de que lhes dei pura e geral quitação, sem que jamais em tempo algum, ele vendedor nem seus herdeiros possa reclamar esta venda, ante se obrigara a fazê-la boa. E pelas referidos (Folhas 11) compradores que pagaram a devida impostos, foi dito que aceitavam a presente [...]

E digo assim outorgaram, abaixo assinaram com as testemunhas presentes José de Medeiros Borges e Álvaro Pereira de Cerqueira, assinando a rogo do comprador João Cardozo Cazumbá, por não saber escrever, Francisco da Silva Menezes que todos assinaram depois de lida por mim[ilegível] Pedreira de Cerqueira, escrivão de 
paz interinamente juramentado, no impedimento do atual, que a escrevi (Escritura de Compra e Venda de Terras. 1879. BAHIA, Arquivo do Fórum Ministro João Mendes, Livro do Tabelionato n. 2)

Se não fosse o sobrenome, a escritura acima, seria apenas mais uma das muitas ocorrências de compras de terras na Freguesia de São Gonçalo dos Campos, nas décadas finais do século XIX. Mas o sobrenome, Cazumbá, carregava um enigma a ser decifrado. Quem era mesmo este João Cardozo Cazumbá? Um abastado comprador de terras que decidiu se consorciar com Manoel Ferreira de Cerqueira que havia sido adjudicada pelo juiz de órfãos da cidade de Santo Amaro? Na escritura consta, também, que não sabiam ler nem escrever, realçando ainda mais as interrogações sobre a identidade desse sujeito.

Semelhante a águia que defere voo, sem interdição das ruínas e dos tempos, porque o investigador se apropria destes sinais - voei por sobre os destroços dos indícios dos documentos até à África, no incansável questionar sobre mistérios que escondiam os Cazumbá. Deste modo, recorrendo aos linguistas busquei a primeira constatação que importa saber sobre a etimologia da palavra.

\section{Rastreando o nome: microanálise etimológica de Cazumbá}

Diretamente Lopes (2004: 180) ofereceu as primeiras asseverações afirmando que a palavra é de origem banto. Sua presença e significado no Brasil têm a ver com os ramos desses povos cujos membros foram trazidos da África ou vieram como comerciantes, uma vez que o termo tem origem em África. Embora seja do grupo etimolinguístico Cazumbi, Zimbi, Nzumbi, originário do Kibundo Nzumbi, pertencente ao macro grupo etnolinguístico Bantu (LODY, 1999: 6) o seu conteúdo enquanto instituição sociopolítica é resultado de uma longa história de migração que se processou no centro africano a partir de 868 (VANSINA, 1988). Sendo assim a compreensão da adoção do nome pela população não branca no Brasil está em estreita relação com a trajetória e a formação dos falares africano de origem Bantu em África e a diáspora que sofreram estes povos ao longo dos três séculos de escravidão na América (HALL, 2003). 
Contudo, as línguas africanas no Brasil encontram-se marcadas pela ruptura de sua continuidade no espaço original, no convívio de uma heterogeneidade linguística pela presença da língua portuguesa, das línguas indígenas e de outras línguas africanas nas diferentes épocas e nos diferentes espaços geográficos. Assim, a análise dos léxicos africanos deve ser contextualizados a partir da chegada de diversos grupos negros para o trabalho escravo na lavoura de fumo e açúcar. Exemplo do Cafundó ${ }^{2}$, em que o léxico de origem banto provocou o questionamento sobre a presença e a permanência de línguas africanas no Brasil e a possibilidade dessa fala ser procedência crioula.

Ainda, de acordo com Queiroz o dialeto de Tabatinga ${ }^{3}$ possui um pequeno vocabulário de origem africana, banto (quimbundo, principalmente), conservando muitos termos semelhantes aos do Cafundó, com morfemas derivacionais e flexionais do português arrolados aos prefixos de origem africana. Ca-, por exemplo, de camona "criança", nas línguas bantos marca o grau diminutivo (QUEIROZ, 1998:79). De acordo com Silva (2011: 3) atualmente existe famílias com sobrenome Cazumbá em África: Angola e Moçambique que dispõem de palavras que levam o mesmo prefixo:

"Kazumbá, Kazumba ou ainda Zumba; existem nomes em Angola, no sul temos muitas pessoas com esse nome[...] a sua pergunta seria se é nome próprio ou sobrenome[...]? Em primeiro lugar os nomes e sobrenomes se confundem muito em Angola, eu tenho certeza que Zumba pode ser nome próprio ou sobrenome de alguém, o que difere em Angola por vezes [é o] grau, por exemplos: em todas línguas bantas, a palavra que leva o prefixo [ka] Ka-zumba igual o

2 Cafundó é um bairro rural situado no município de Salto de Pirapora com aproximadamente 150 km de São Paulo. Sua população, predominantemente negra, divide-se em duas parentelas: a dos Almeida Caetano e a dos Pires Pedroso. Com a população de 80 habitantes nem todos detêm o título legal das terras. Constam que estas foram doadas a dois ancestrais escravos pelos antigos senhores e fazendeiros, pouco antes da Abolição, em 1888. Nela plantam milho, feijão e mandioca e, ainda, criam galinhas e porcos, apenas para atender parte de suas necessidades de subsistência. Também trabalham como diaristas, boias-frias e como empregadas domésticas. A fala do Cafundó é uma variedade do português regional, um dialeto rural, caracterizada por um léxico de origem banto, quimbundo principalmente, que os representa como africanos no Brasil. O léxico contém cerca de 160 itens, com 15 verbos e 2 advérbios. Em relação aos usos que ainda SLENES, Robert W. "Histórias do cafundó", In. VOGT, Carlos e FRY, Peter, Cafundó - A África no Brasil. São Paulo: Cia das Letras; UNICAMP, 1996.

3 Tabatinga é um grupo de negros localizados na cidade de Bom Despacho (MG), a $140 \mathrm{~km}$ de Belo Horizonte. Possuem morfemas derivacionais e flexionais do português, embora seja possível identificar em diversos termos prefixos de origem africana. QUEIROZ, S. Pé preto no barro branco: a língua dos negros da Tabatinga. Belo Horizonte: Editora da UFMG. 1998. 
grau diminutivo. O pai no caso tem o nome de Zumba grau superlativo, e essa é primeira confusão, e a segunda é de não termos regra de nomes e sobrenomes em Angola. E agora o a letra [k] foi substituída por portugueses [c] e naturalmente foi evoluída para acento. Normalmente esse nome é comum na etnia Chokwe, Ganguela e Nhemba, e os chokwes são famosos nos rituais e máscaras, Zumba também está relacionado à divindade [...] (Relato de Fernando Wilson Sabonete, natural de Angola, da etnia Nhaneka-humbi presente no texto de SILVA: 2011:3)

Numa análise diacrônica do léxico Cazumbá é possível identificar o prefixo Ca de origem africana, o morfema identificador de classe nominal diminutiva, contudo, a apreciação não deve excluir os lugares sociais, econômicos e culturais onde as "heranças" transitam, uma vez que transplantadas para o Brasil às experiências dos sujeitos podem revelar traços de seu longo e intenso contato com o português, elaborações elucidativas para compreensão do significado.

A palavra Cazumbá também se veste de mito em diversos personagens no território brasileiro. O bumba-meu-boi no estado do Maranhão faz referência à cultura africana na tradição popular brasileira (MATOS, 2010). O folclore maranhense apresenta bois com um ritmo compassado, com badalo, pandeirões, chapéus bordados com penas de ema e a presença do cazumbá. O cazumbá nesta situação se relaciona em meio aos espíritos e aos humanos.

Para além da tradição popular no Maranhão o mito perpassa o imaginário popular do Recôncavo e do Sertão no emblemático personagem José Ferreira Cazumbá. A tradição oral mistura ficção e realidade, alguns autores apresentam-no como ex-escravo, exoficial de justiça, delator do consorte Lucas da Feira (Jornal Folha do Norte- 28/01/1939. Ano de referência 1848. p. 101. no 1542. AMSMG; ROMERO, 1954; MORAIS FILHO, 2002; MOURA, 2004; CAMPOS, 1957; LIMA, 1990).

\section{Seguindo as pistas: investigando os documentos oficiais}

A tradição oral de moradores do Bairro São João do Cazumbá, em Feira de Santana, Bahia, transmitia que José Ferreira Cazumbá 
em tempos antigos era amigo de Lucas da Feira e que em diversos momentos ambos se esconderam em uma árvore robusta e frondosa que existia no bairro, todavia, Cazumbá traiu Lucas entregando o esconderijo as autoridades (CARVALHO, 2008). Essa narrativa se consolida nos argumentos para afirmar que o nome do bairro São João do Cazumbá se refere à presença deste na localidade. Outros contrapõem a este discurso narrando que a origem do nome tem a ver com a presença de um fazendeiro por nome João Cazumbá.

Enveredando em torno das pegadas deixadas nas fontes oficiais foi possível desvendar os mistérios que envolvia a tradição oral. Encontrei jornais publicados no século XX com notícias do século XIX. Supostamente esses noticiários, publicados em 1938 a 1948, período do governo Vargas, momento de golpe de Estado, traziam mensagens subliminar expondo histórias de sujeitos viveram no século XIX. Além disso, os jornais eram um poderoso instrumento de comunicação no qual segmentos da sociedade exprimem publicamente as suas opiniões, uma vez que, entre os anos 20 e 40 os jornais era expressão da elite pensante do país. Assim, para não provocar reações das forças opressivas do governo recontava muitas vezes lembrado, o mito do "herói" da resistência à escravidão. Supostamente os auditores de jornais para que a população feirense se mobilizasse contra a ditadura varguista (CAPELATO, 1991/1992). Nesse contexto os jornais feirenses faziam alusão a Lucas e Cazumbá em diversas situações:

Uma multidão de crianças desleixadas pelos pais, pela escola, vagabundando pelas ruas e pelas roças, frequentando pelas mansões terríveis dos vícios. [...] Uns trilhando no latrocínio, outros na bebedice, outros na prostituição, mais outros na valentia e consequentemente nas rixas entre os companheiros, modos todos estes como se iniciou Lucas pelas ruas desta cidade. [...] Vi, então por uma imagem do pensamento, todos estes Lucas e Cazumbás incipientes fermentando em seus espíritos os produtos de todas essas perversões, uns porque não têm pai, nem mãe, nem avós, nem tutores, são sós na sociedade, outros porque os têm e são tanto os outros pervertidos morais. [...] (Jornal O Município. n. 48, 22 de maio de 1909, p. 1-3) 
A memória social no início do século XX discorria que "os salteadores", Lucas e Cazumbá, por vezes bandidos, tornaram-se exemplos às crianças em Feira de Santana, pois os pais e a escola deixavam "vagabundando" pelas ruas e pelas roças, convivendo com vícios, latrocínio, bebidas, prostituição e brigas. Este episódio retrata os bastidores da memória feirense a respeito do século XIX. Em linhas gerais existia um forte imaginário social projetando perfis e enredos no tocante à curta trajetória do personagem Cazumbá. A luz projetada sobre o protagonista levou-me a questionar sua real aparição naquela conjuntura social. Entretanto, continuei seguindo indícios na tentativa de esclarecer as minhas indagações concernentes as relações construídas no seio de Feira de Santana.

Ao aplicar o método de Zadig (GINZBURG, 1989) nos jornais e manuscritos consultados no Arquivo Monsenhor Renato Galvão/Casa do Sertão/UEFS, do século XIX e início do século XX, em Feira de Santana me levou ao registro de óbito de 1857,

Morte de Cazumbá (1857). José Ferreira Cazumbá, casado em (sem identificação) nupciais com Dona Rosa de Jesus, seus filhos natural de São José das Itapororocas. Preso por ter morto a cacete Marcelino Lopes da Silva, em oficial de Justiça evadiu-se em comprade de Lucas no batismo de Calatino, filho do salteador. Para obter o perdão e a prometida recompensa e outros auxílios (Vide Vida Feirense 4/04/1942 -Livro I, Miscelâneal Monsenhor Renato Galvão, p. 382, AMSMG).

Tais pistas foram estímulos necessários para continuar a investigação. Observei alusão ao Jornal Vida Feirense, a data de sua morte e o nome da mulher. Isto significava que este personagem não se tratava apenas de um mito presente no imaginário feirense. Entretanto, nos jornais, bem como em quase todos os indícios, o personagem Cazumbá aparece como coadjuvante de Lucas da Feira.

O jornal Folha do Norte, 20 de maio de 1939 (Jornal Folha do Norte, 20 de maio de 1939. AMSMG) sinalizava que José Ferreira Cazumbá, oficial de Justiça, nos tempos remotos tornou-se companheiro de Lucas da Feira, por isso, conhecia os locais de esconderijo do "cúmplice". Continua narrando que em diligência 
de justiça, Cazumbá, feriu violentamente um sujeito. Vindo este a óbito, o oficial, foi "Submetido a processo, foi pronunciado, e então ocultou-se". O juiz cons. Góes, incumbiu a José Ferreira Cazumbá "a missão de capturar Lucas, em troca de livrá-lo do crime", assim, Cazumbá organizou uma expedição a qual Lucas foi capturado.

Um ano depois da notícia acima o mesmo jornal (Jornal Folha do Norte, 1940. AMSMG) divulga um noticiário, de 1865, sobre a prisão de Lucas. Cazumbá aparece como compadre e denunciante do esconderijo do salteador. De acordo ao noticiário José Ferreira Cazumbá andava guiando a polícia pelas serras e matos até que aprisionou o bandoleiro, na Pedra do Descanso, dando-Ihe um tiro. Recebendo em troca 4.000,00 contos e absolvição dos crimes que "não eram poucos".

O Jornal (Jornal Folha do Norte, 1948. AMSMG) publicado em 1848 detalha os episódios precedentes à prisão de Lucas, entretanto, não reconhece a participação de José Cazumbá. Pontua que o bandido se ocultava em companhia de Benedito (cúmplice) e uma moça que raptara num rancho de palhas com ferimentos no braço ocasionado pelos tiros deflagrados pelo policial Serafim.

Em cortejo à delegacia escoltado pela polícia de "baioneras" que mantinha o povo à distância abrindo espaço para os que carregavam Lucas na rede, por causa de seu machucado e "indefeso, implorou a Cazumbá", que o acompanhava ao lado dos condutores para lhe salvar a vida. Nestas investigações notei que os jornais tentavam criar a imagem para Cazumbá como um bandoleiro arrependido dos seus crimes, ao mesmo tempo, como um ex-observador da lei.

No arquivo o Arcebispado, em Feira de Santana, foi encontrado o Registro de Óbito que continha informações a respeito da situação civil. $O$ que significa dizer que se existia uma certidão atestando a morte nos registros eclesiásticos é porque esta pessoa vivia. Neste observa-se, ainda, informações a respeito de sua situação civil, raça e idade e morte. O falecimento se deu em 6 de abril de 1856, casado, pardo, com 40 anos de idade, sendo sepultado no cemitério de São José das Itapororocas (Livro de Óbito, 1856. AAFS). Não é conhecido a causa da morte, para tal, carece maiores investigações. Persiste a pergunta: quem foi José 
Ferreira Cazumbá? Por que o nome tem tanta representação no cenário do Sertão e Recôncavo baiano?

Todo desenho acerca desta figura misteriosa pode ter relação com outras situações ou apenas com o sobrenome Cazumbá por força de sua origem etimológica. Algumas pistas sinalizam para a presença da denominação Cazumbá desde o período colonial no século XVIII. No livro de Luiz Alberto Moniz Bandeira (2000) nos capítulos IX e $X$ aparece José Pires de Carvalho e Albuquerque, secretário de estado e proprietário de muitos engenhos, dentre eles o Engenho Cazumbá. Esse mesmo engenho é citado por Schwartz (1988) no livro Segredos Internos na página 321. De acordo com Schwartz os escravos deste engenho "procuravam companheiras entre as ex-escravas e suas descendentes que viviam nas imediações do engenho" (SCHWARTZ, 1988: 321). Valim (2012), em Corporação dos enteados, página 105, destaca que o Engenho Cazumbá, em 1859, foi arrematado pelas religiosas do Convento da Santa Clara do Desterro da Bahia, ao devedor Baltazar de Vasconcelos Calvacanti, pai da abadessa Catarina dos Anjos e vendido a José Pires e a sua esposa, pela quantia de $7.400,00$ reis.

Mapa 1: Fronteiras de engenhos ao longo do Rio Jacuípe

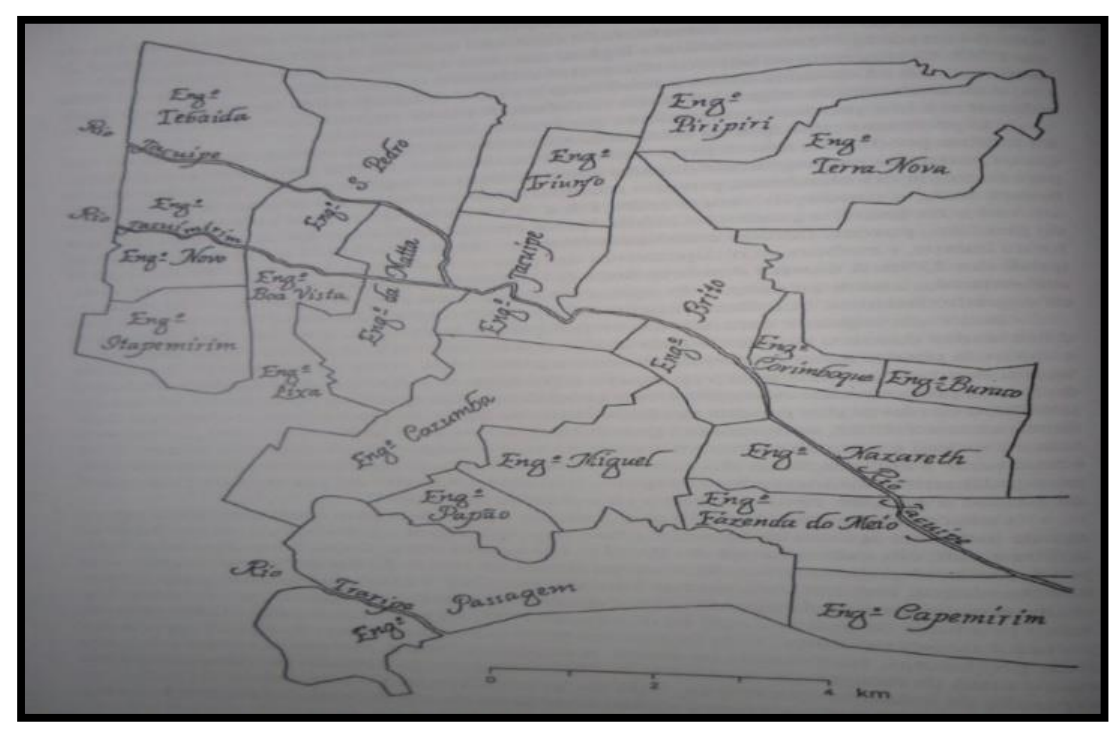

Mapa: Fronteiras de engenhos ao longo do Rio Jacuípe. Baseado em um mapa de 1864 no Mosteiro de São Bento em Salvador, no qual aparece o engenho denominado Cazumbá. In. SCHWARTZ, Stuart B. Segredos Internos: engenhos e escravos na sociedade colonial 1550- 1835. SP: Cia. das Letras, 1988 . p. 344. 
Fraga (2006: 299) também menciona o engenho Cazumbá, no final do século XIX, localizado na freguesia de Rio Fundo. Este autor não cita o proprietário, apenas exibe o trabalhador rural envolvido em um conflito. Possivelmente este engenho seja 0 mesmo citado pelos autores anteriores. Embora faltando informações acerca da origem da denominação do engenho tais autores referem-se à localização deste no Recôncavo. Já Luiz Freire revela $O$ engenho Cazumbá em sua dissertação (FREIRE, 2007:73) localizado em Feira de Santana. Esse engenho foi catalogado nos inventários do Coronel Joaquim Pedreira de Cerqueira. Nele havia 101 escravos, os quais trabalhavam em diversas ocupações. O proprietário possuía também fazendas de gado: Bonita, Mocambo e Ponta do Poço, em Camisão, atualmente denominada de Ipirá, localizada a $96 \mathrm{~km}$ de Feira de Santana.

No Arquivo Cível do Fórum Felinto Bastos, em Feira de Santana, encontrei duas escrituras de compra e venda de escravos de 1865. A primeira feita pelo Reverendo Vigário José da Purificação Meneses, da Freguesia de Santa Bárbara, através do procurador Reverendíssimo José Cupertino de Araújo ao Coronel Joaquim Pedreira de Cerqueira, Freguesia da Purificação dos Campos, do escravo Eugenio, crioulo, 20 anos, natural das "Uriçangas", do termo da Purificação, pela quantia de 1.200 .00 reis (Escritura pública de compra e venda, Vila de Feira, 23/set./1865 - fls. 183v-184v, Arquivo Cartorial, Fórum Felinto Bastos, Feira de Santana). Na segunda, com o mesmo objetivo da anterior, - Coronel Joaquim Pedreira da Cerqueira compra o escravo Antônio, jejê, 40 anos mais ou menos, solteiro, serviço da lavoura, pela quantia de 900.00 reis, ao proprietário Salustiano Aurelyo da Silva. Ambos escravos para trabalhar no Engenho Cazumbá/Purificação dos Campos (Escritura pública de compra e venda, Vila de Feira, 25/set/1865- fls.186v-187v, Arquivo Cartorial, Fórum Felinto Bastos, Feira de Santana).

Observa-se que ambas escrituras destacam 0 engenho denominado Cazumbá, pertencente ao Coronel Joaquim Pedreira de Cerqueira, o mesmo citado por Freire (2007). Nas escrituras de compra e venda de 1865 é indicado que o engenho localiza-se em Purificação dos Campos/Santo Amaro e, não em Feira de Santana como sugeriu o autor. Neste contexto a denominação, 
provavelmente, tenciona a relação com a África, mesmo que a relação fosse senhor-escravo, lance que carece mais buscas, talvez um retorno ao início do século XVIII, especialmente a população escrava do engenho.

Voltando ao personagem Cazumbá, no final da década de 1950, Sabino de Campos escreveu um romance intitulado "Lucas o demônio negro" que narra a história de Lucas da Feira apresentando episódios que marcam a construção de uma memória coletiva acerca de José Ferreira Cazumbá, constituída a partir do contato com Lucas. Tais narrativas trazem à guisa de questionamento reflexões a respeito do sobrenome Cazumbá que representa a força africana no cotidiano da região.

Sabino de Campos fez uma descrição fisionômica de José Cazumbá, descrevendo-o como um indivíduo alto, forte, pardo, de cabelos crespos, testa ampla e limpa, olhos penetrantes, boca, nariz e orelhas regulares, mãos e pés grandes, barba raspada (CAMPOS, 1957: 120), casado pela terceira vez, não possuía filhos. Na descrição o autor faz menção sua fisionomia forte e superior a Lucas, sendo admirado por este que em reconhecimento a suas qualidades e posição elevada, respeito e amizade pede-lhe para batizar seu filho Colatino em uma missa realizada em São José das Itapororocas. Nesta versão Cazumbá era irmão de Gregório um antigo proprietário de Lucas. O detalhamento feito por Campos avulta os traços raciais de Cazumbá, logo, sua força física e respeito social (BARTH, 1998) até mesmo por Lucas da Feira que o admira e era-lhe subserviente.

Os documentos indicam que José Ferreira Cazumbá era morador da Freguesia de São José das Itapororocas. Na idade de 40 anos encontrava-se casado pela terceira vez, sendo a última esposa Ana Rosa de Jesus. Em diligência ao povoado de Nagé, Feira de Santana, em companhia de Marcelino Lopes da Silva, assassinou um velho sertanejo a pauladas, motivo para ser preso e processado. Depois de algum tempo conseguiu fugir da cadeia escondendo-se na casa do pai de sua segunda mulher Luiz da Cunha Vieira.

Segundo Lima, Cazumbá, enquanto oficial de justiça, havia participado da prisão de Januário, escravo, membro do bando de Lucas. Ele foi responsável, 07/01/1843, em levar a intimação a 
Antônio Amorim Bezerra, proprietário de Januário, para que fosse reconhecer o cativo (Correspondência - Juízes - Feira de Santana - 1843 - 1847. Of. 02.03.1843 - Maço, 2373 - APEB).

Quando o governo afixou edital, em 13 de maio de 1846, convocando a população para capturar o salteador em troca de 4 contos de réis, Cazumbá, sendo considerado um criminoso por que do homicídio do sertanejo, prevendo a absolvição, tornou-se o principal responsável pelas buscas e aprisionamento de Lucas.

Lima destaca que antes da publicação deste edital outro já havia sido lançado oferecendo o prêmio de 2 contos de réis, entretanto, quase ninguém se interessou pela quantia (LIMA, 1990). Possivelmente $O$ aparente desinteresse fosse pertinente $a$ dificuldade e o perigo atido a figura do bandoleiro. Além disso, nesta época José Cazumbá ainda não necessitava de anistia, fato que provocou grande inquietação social e, provavelmente, a associação de Cazumbá como um dos componentes do bando.

Assim, quando o edital foi divulgado o ex-sogro Luiz da Cunha alertou Cazumbá concernentes as vantagens que ele teria se conseguisse aprisionar Lucas. Além dos 4 contos granjearia absolvição do delito. Cazumbá, por sua vez, incube-o a procura do juiz e delegado do município de Feira, Dr. Leovegildo de Amorim Figueiras, para apresenta-lhe as propostas para capturar o tão procurado salteador (CAMPOS, 1957; Jornal Folha do Norte28/01/1939. Ano de referência 1848. p. 101. n 1542. AMSMG).

Tudo certo, Cazumbá dispõe de plano de captura e auxiliares: Manoel Gomes, sertanejo, odiava Lucas por este ter violentado a sua filha Ana Gomes, virgem, parda; Bendito da Tapera, crioulo; Aprígio, pardo; José Luiz Gonzaga; Bernardino; Serafim; Cipriano de Freitas, escravo; Porfirio, escravo do coronel Pedreira; Luciano Plácido e Marcelino (LIMA, 1990, CAMPOS, 1957, Correspondência - Polícia - 1828-1849, maço 3113 - APEB. Id., Polícia - of. 09.04.1848 - maço 6383 - APEB. Id., Ibid., of. 17.04.1848 - maço 6383 - APEB). Assim, segundo Barth as etnias podem ser construídas e elaboradas contextualmente para além das especificidades raciais. "O bando" formado especifica que é construído um grupo que envolve diferentes características raciais. E não que os traços raciais distinguem a etnicidade, isto porque, talvez, o que esteja se consolidando naquele "bando", seja 
uma formação nos moldes étnicos que inclui vários traços raciais. Portanto, os fluxos e contatos estabelecidos por José Cazumbá posiciona-o entre os sujeitos de cor e escravos de Feira de Santana na primeira metade do século XIX.

Cazumbá, - 23 de janeiro de 1848, segunda feira - manhã posterior a festa da Capela e arraial de Nossa Senhora de Humildes, filial da Paróquia de São Gonçalo dos Campos, três léguas de Feira de Santana, pela estrada de Santo Amaro, ficou sabendo pelo escravo Cipriano de Freitas, que Lucas descansava sob a sobra de uma árvore - quixabeira - no local que ficava próximo a estrada que ligava o Mochila ao Buris, nas imediações da Pedra do Descanso, após comparecer à festa (CAMPOS, 1957).

Bem informado, dirigiu-se ao local acompanhado por Manoel Gomes onde avistou o salteador e deferindo-lhe um tiro que acertou o braço esquerdo. Aquele, porém, baleado fugiu para seu rancho, na fazenda Tapera, próximo ao poço do Gurunga (LIMA, 1990: 1990), imediações do Rio Jacuíp, local que foi capturado na companhia de Maria Romana.

Cazumbá com agudeza de espírito investigou minuciosamente o local, apreendendo armas, munições, bálsamo, capanga 4 , algumas moedas, uma faca de ponta, outros pertences e remédios destinados ao tratamento do ferimento no braço (CAMPOS,1957, p. 146). Neste conjunto de narrativas observa-se a identificação de árvore, estrada, poço, pedra, bálsamo que pleiteiam os espaços de crenças e saberes de origem africanas (LESSA, 2005; BARTH, 1998; PARÉS, 2006; PARÉS, 2005; REIS, 1997)

Com o aprisionamento de Lucas, Cazumbá, recebeu o prêmio de 4 contos de reis, o qual foi repartido com os auxiliares, ficando com o quinhão de 2 contos de réis (LIMA, 1990, p. 200) e a absolvição do homicídio. Voltou a ocupar cargo de oficial de justiça, posição importante para desaparição do processo que era considerado um criminoso (CAMPOS, 1957).

Além de tudo que almejava recebeu da população feirense o prestígio que antes não tinha: "e fruindo de novo, a consideração

4 Associado ao valentão ao serviço de alguém para defender a sua pessoa ou os seus interesses; guarda-costas indivíduo que obedece outro por dinheiro. In Dicionário infopédia da Língua Portuguesa [em linha]. Porto: Porto Editora, 2003-2018. [consult. 2018-07-27 15:48:48]. Disponível em: https://www.infopedia.pt/dicionarios/lingua-portuguesa/capanga. 
dos feirenses, enfiava os grossos polegares nas cavas do colete de fusta e inchava o peito dizendo com imponência: - Nada como a posição social do indivíduo!" Campos (1957) dá uma entonação diferenciada ao responsável pelas buscas e pela prisão, pontuando a repercussão social do fato, tornando Cazumbá o mais admirado dos homens, recebendo, sobretudo, uma grande quantidade de donativos de comerciantes de Feira de Santana, São Gonçalo, Cachoeira, São Felix, Muritiba, Santo Amaro, Salvador e de inúmeros particulares (CAMPOS, 1957).

Neste relato José Ferreira Cazumbá recebeu maiores honras do que os jornais e a memória coletiva costumavam ostentar. Portanto, levanto o questionamento, quem foi José Ferreira Cazumbá? Recebeu as honras que Sabino relata no romance? Por que este fato foi esquecido da memória coletiva feirense? Porque este homem aparece, apenas, como um bandido, ligado ao bando de Lucas? Teria sido uma tentativa de apagar a imagem de um homem pardo como um protagonista de tão esperado feito?

O jornal Folha do Norte, 1940, havia uma reclamação relacionada aos oficiais de justiça. Assim, o jornalista advertiu que os oficiais ocupantes do cargo em Feira de Santana chegavam de Santo Amaro, pessoas de cor, que de costume, transgrediam as leis (Jornal Folha do Norte, 1940. AMSMG). Embora não citasse literalmente José Cazumbá, fazia analogia aos tempos passados e a presença de oficiais de cor parda, que cometeu crime. A partir desse dado é possível indicar que Cazumbá fosse de Santo Amaro. É provável, ainda, que seu sobrenome tivesse relação com o Engenho Cazumbá, na presença de escravos de origem banto e através do processo de negociação e especialização da mão de obra (SCHWARTZ, 2001) conquistasse representação, destaque e, consequentemente, a liberdade. Daí deslocamento para Feira onde se tornou oficial de justiça. Bem como discute Poppino (1998) sobre o processo migratório e a chegada de indivíduos de outros locais em Feira de Santana. Igualmente Fraga (2006) destaca a migração, embora seu trabalho dê conta do final do século XIX, é possível sugerir que estes deslocamentos eram comuns bem antes, desde final do século XVIII. Também 0 contexto das revoltas no Recôncavo, entre 1822 a 1835, favoreceu o deslocamento de indivíduos (REIS, 2003; SILVAE REIS, 
1996), bem como, a participação de escravos nestas lutas que, mediante a isso, muitos conquistaram a liberdade.

Entretanto, outros dados negam a chegada de Cazumbá no período denominado "Recôncavo rebelde". Em 1822, foi exposto, no Registro de Povoação do Distrito da Vila de Santa Anna, e da mesma Freguesia, como oficial de justiça, pardo, possuído de fogo, com 3 pessoas sob seu julgo (Registro de Povoação do Distrito da Vila de Santa Anna, e da mesma Freguesia, 1822. AMSMG). O documento não informa sobre sua situação civil, todavia, sabe-se que foi casado por três vezes e que não possuía filhos. Nem tão pouco constam indícios que identificassem seus ascendentes ou parentes.

Notadamente na região do Recôncavo e do Sertão histórias e personagens aparecem ligados as identidades africanas ou miscigenadas. Contudo, os indícios não foram totalmente capturados para estabelecer relações e semelhanças com 0 sujeito que desponta no início do artigo comprando terras em São Gonçalo dos Campos.

Sem a genealogia escrita José Ferreira Cazumbá desapareceria aqui. Todavia os descendentes de João Cardozo Cazumbá, através da tradição oral, acionam parentesco entre ambos. Sendo assim, esse sujeito intrigante reaparece como a fênix nas reminiscências dos Cazumbá pós-abolição.

Ao ser questionado sobre sua família em uma entrevista feita por mim em 2008, em seu escritório de trabalho, na cidade de São Gonçalo dos Campos, José Cazumbá, comissário de menores, afirmou que não conhecia todos de sua família, pois em "São Gonçalo tinha muita gente, outros foram para a Capital". Advertiu, também, que o ex-oficial de justiça, em Feira de Santana, José Ferreira Cazumbá (Entrevista de José Cazumbá, Comissário de Menores, concedida em 12 de abril de 2008), responsável pela prisão de Lucas da Feira, era seu tio. Igualmente Maria de Lourdes Cazumbá (Entrevista concedida em 16 de maio de 2012, São Gonçalo dos Campos), escrivã do cartorial civil, expôs a sua ancestralidade ao oficial de justiça. Lourdes, nesta entrevista realizada no fórum o qual trabalhava, retrata José Ferreira Cazumbá, como seu primeiro ancestral que ela teve 
conhecimento através dos depoimentos narrados por seus parentes.

Tanto a personalidade, José Ferreira Cazumbá, em Feira de Santana, como a família, em São Gonçalo dos Campos, têm uma forte representação social. Silva (2011), no artigo intitulado "Cazumbá: História e memória no Recôncavo Baiano (1888-1950)" adverte que:

Por exemplo, uma funcionária do Fórum, quando soube do nosso interesse, disse-nos: "O sobrenome Cazumbá em São Gonçalo é pomposo, vale mais do que dinheiro". Aliás, as informações apontavam para uma distinção da família Cazumbá em relação aos demais descendentes de africanos residentes na cidade (SILVA, 2011).

Neste sentido surgem novos questionamentos sobre o mistério por traz dos indivíduos e do nome Cazumbá? Quais as experiências estavam inseridas? Como se formou a família em São Gonçalo dos Campos? A investigação segue no sentido de desvendar estes mistérios. Por que os indivíduos vão aparecer no século XX com ampla representação, bem como surgem Avenidas e Bairro em São Gonçalo e Feira de Santana denominadas Cazumbá?

Assim, o personagem do início deste artigo, João Cardozo Cazumbá, compareceu no cartório, em 30 de junho de 1879, consorciado a Manoel de Ferreira de Cerqueira, moradores desta freguesia, como compradores e o Major Francisco Antônio de Carvalho, morador da cidade de Santo Amaro, como vendedor. Presentes partes, o escrivão de paz interinamente juramentado, [ilegível] Pedreira de Cerqueira, declara ser os compradores conhecidos e sem impedimento para comprar as terras, casa e benfeitorias da fazenda antigamente denominada Várzea, Sobrado, na localidade Cruz, pela quantia de 1: $800 \$ 000$ reis $^{5}$ (um conto e oitocentos mil reis) (Escritura de Compra e Venda de Terras. 1879. BAHIA, Arquivo do Fórum Ministro João Mendes, Livro do Tabelionato $n .2)$. Sendo quitado o valor, o vendedor e seus herdeiros em tempo algum poderiam reclamar a venda. Assim,

5 Conto de réis - Moeda portuguesa que corresponde a um milhão de reais ou um milhar de mitréis. Mil réis - Milhar do real. Ver NEVES, Erivaldo Fagundes. Posseiros, rendeiros e proprietários: estrutura fundiária e dinâmica agromercantil no Alto Sertão da Bahia (1750-1850). Recife: [s.n.], 2003. 
assinam com as testemunhas presentes José de Medeiros Borges e Álvaro Pereira de Cerqueira, assinando a rogo do comprador João Cardozo Cazumbá, por não saber escrever, Francisco da Silva Menezes.

A fazenda foi adjudicada pelo Juiz de órfãos da Cidade de Santo Amaro, Doutor Joaquim Alves de Almeida Freitas, do finado Comendador Antônio Lopes Ferreira e Souza, que era seu devedor. Sendo as demarcações são: ao sul com terras de João do Mayo Machado; oeste do Padre Gonçalo de Souza e leste e norte com terras de Estevão Machado (Escritura de Compra e Venda de Terras. 1879. BAHIA, Arquivo do Fórum Ministro João Mendes, Livro do Tabelionato n. 2). O mapa abaixo sugere a possível localização da fazenda.

\section{Mapa 2: São Gonçalo dos Campos}

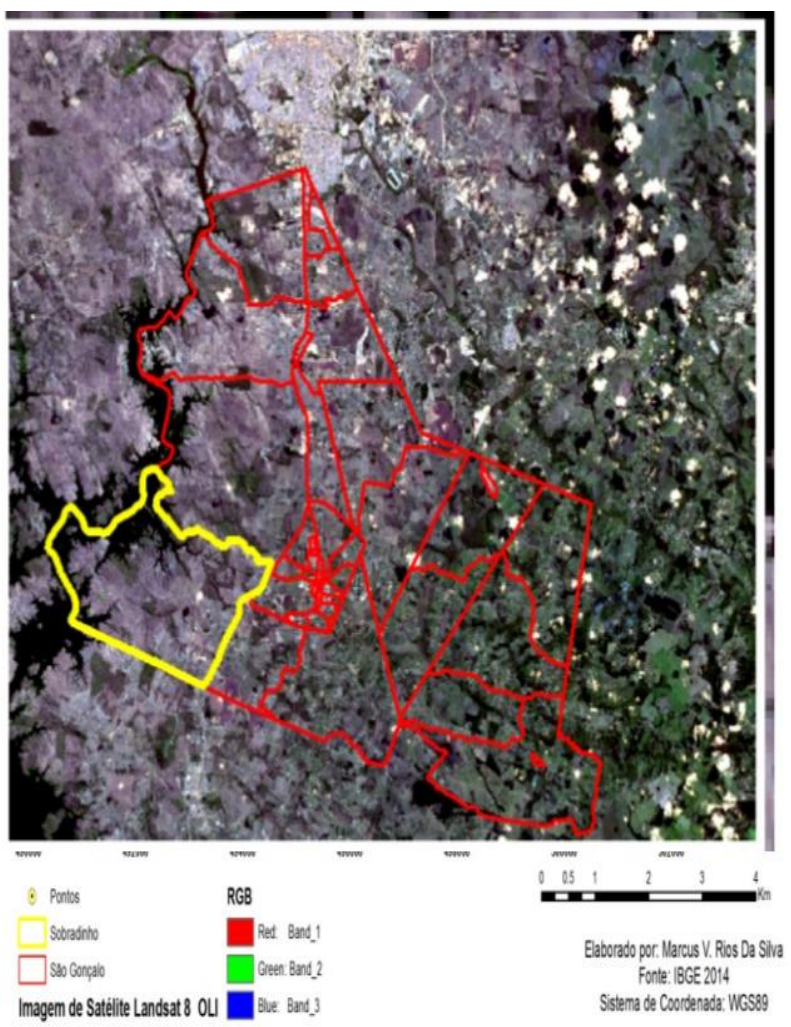

Fonte: USGS. Serviço Geológico do Governo dos Estados Unidos. Acessado no dia 3 de junho de 2014 em: http://earthexplorer.usgs.gov/

Embora este seja o primeiro documento que saltou aos meus olhos esta não foi a primeira aquisição de terras realizada por 
Cazumbá. Anexo ao Pedido de Embargo, 1895, estava um translado de venda e compra de terras, de 30 de maio de 1874. No documento Maria Joaquina da Silva, viúva de José da Silva, vendeu ao senhor João Cardozo Cazumbá, 33 braças $^{6}$ e meia de terras da Fazenda Terra Dura, pelo valor de 300 mil reis. Recebendo do comprador 250 mil reis em moeda e o restante, 50 mil reis, receberia a partir de 2 meses da data compra, ficando a terra penhorada (Pedido de Embargo, 1895. Arquivo Cartoriall Fórum João Mendes. São Gonçalo dos Campos). Mediante essa compra João Cazumbá tornou-se um proprietário de terra no local denominado Cruz e quatro anos mais tarde irá comprar com Manoel de Ferreira de Cerqueira a fazenda Sobrado.

\section{Considerações finais}

Pois bem, em inventários, registros de compra e venda de imóveis e na tradição oral, encontrei os vestígios de João Cazumbá, bem como de outros sujeitos que tiveram suas vidas influenciadas por diversas transformações que sucederam as últimas décadas do século XIX. Vale destacar que a tradição oral foi de crucial importância para identificar a ancestralidade da família desde a primeira metade do século XIX. Assim, nas entrevistas com os descendentes entre idade entre 40 e 80 anos foram indagados a respeito das histórias contadas por seus pais e avós concernente as experiências de seus antepassados no sentido de reconstituir e analisar a ascendência, as relações matrimoniais, o trabalho na roça, os contatos com os diversos sujeitos sociais, a religião e cultura.

Observa-se que o sobrenome remonta às experiências dos povos centro africano e no Brasil essa herança foi ressignificada a partir do contexto em que a família estava envolvida. Marcada pelo forte referência etnicorracial e a posição social de destaca em cargos socialmente importante ou na obtenção de bens, como foi o caso da compra de terras por João Cazumbá, ao mesmo tempo em que se trata de uma família na condição de cor que mantiveram o sobrenome africano (bantu) posto o contexto de escravização.

61 braça $=2,2$ metros. 


\section{Referências Bibliográficas}

BANDEIRA, Luiz Alberto Moniz. O Feudo: A Casa da Torre de Garcia D' Ávila RJ: Civil. Brasileira, 2000.

BARTH, F. Grupos Étnicos e suas fronteiras. In: POUTGNAT \& STREIFFENART. Teorias da etnicidade. Seguido de grupos étnicos e suas fronteiras de Fredrik Barth. São Paulo: UNESP, 1998.

BARTH, F. Grupos Étnicos e suas fronteiras. In: POUTIGNAT, P. Teorias da etnicidade. Seguido de grupos étnicos e suas fronteiras de Fredrik Barth, Philippe Poutignat, Jocelyne Streiff-Fenard. Tradução de Elcio Fernandes. São Paulo: UNESP, 1998.

CAMPOS, Sabino. Lucas o demônio negro. Romance folclórico baiano, Rio de Janeiro, 1957

CAPELATO, Maria Helena. "O Controle e os Limites da Liberdade: Imprensa Paulista (1920-1945)" In: Revista Brasileira de História, São Paulo, v. 12, n 23 - 24, pp. 55 -75, set. 1991/ ago. 1992.

CARVAlHO, M. C. M. de. Comunidades Negras Rurais e Memórias de Quilombos. (Monografia conclusão do curso de graduação)Feira de Santana: UEFS, 2008.

CHALHOUB, Visões da Liberdade; GINZBURG, Carlo. Mitos, emblemas, sinais: morfologia e história. São Paulo: Companhia das Letras, 1989.

Dicionário infopédia da Língua Portuguesa [em linha]. Porto: Porto Editora, 20032018. [consult. 2018-07-27 15:48:48]. Disponível em: https://www.infopedia.pt/dicionarios/lingua-portuguesa/capanga

FRAGA, Walter. Encruzilhadas da Liberdade: histórias de escravos e libertos na Bahia (1870-1910) Campinas, SP: Editora da UNICAMP, 2006

FREIRE, Luiz Cleber Morais. Nem tanto ao mar, nem tanto à terra: agropecuária, escravidão e riqueza em Feira de Santana, 1850- 1888. Dissertação de Mestrado. UFBA. 2007.

HALL, Stuart. Da Diáspora: Identidades e mediações culturais. Belo Horizonte, editora da UFMG, 2003.

LESSA, Luciana Falcão. Senhoras Do Cajado: Um Estudo Sobre A Irmandade Da Boa Morte De São Gonçalo Dos Campos.(Dissertação de Mestrado em História). Salvador: UFBA, 2005

LIMA, Zélia de. Lucas Evangelista: o Lucas da Feira; estudos sobre a rebeldia escrava em Feira de Santana. 1807 - 1849. (Dissertação de Mestrado). Salvador: UFBA, 1990.

LODY, R. Cazumbá. Máscara e drama no boi do Maranhão. Museu do Folclore Edison Carneiro, Rio de Janeiro: Ministério da Cultura, 1999. 
LOPES, Nei. Novo Dicionário Banto Do Brasil. RJ: Pallas, 2003, p.76; LOPES, Nei. Enciclopédia Brasileira Da Diáspora Africana. SP: Selo Negro, 2004.

MATOS, Elisene Castro. CAZUMBAS: Etnografia de um personagem do bumbameu-boi. Dissertação: São Luís, 2010.

MORAIS FILHO, Melo. Festas e Tradições Populares do Brasil. Brasília: Senado Federal (Coleção Biblioteca Básica Brasileira) 2002.

MOURA, Clóvis. Dicionário da escravidão Negra no Brasil. SP: Edusp, 2004.

NEVES, Erivaldo Fagundes. Posseiros, rendeiros e proprietários: estrutura fundiária e dinâmica agromercantil no Alto Sertão da Bahia (1750-1850). Recife: [s.n.], 2003.

PARÉS, LUÍs Nicolau. A formação do Candomblé: história e ritual da nação jeje na Bahia. Campinas, SP: Editora da UNICAMP, 2006.

PARÉS, Luís Nicolau. O Processo de Crioulização no Recôncavo (1750- 1880). Revista Afro- Ásia, v. 33, p. 87- 132. 2005.

POPPINO, R. Feira de Santana. Salvador. Itapoã, 1998.

QUEIROZ, S. Pé preto no barro branco: a língua dos negros da Tabatinga. Belo Horizonte: Editora da UFMG. 1998.

REIS, João José. A tradição rebelde ll: revoltas escravas na Bahia independente. In.: Rebeliões Escrava no Brasil: a história do levante dos malês em 1835. Edição revista e ampliada. São Paulo: Companhia das Letras, 2003.

REIS, João José. Identidade e Diversidade Étnica nas Irmandades Negras no Tempo da Escravidão. Tempo, Rio de Janeiro, Vol. 2, n. 3, 1997.

ROMERO, Sílvio. Folclore Brasileiro 1 - Contos Populares do Brasil. RJ: Livraria José Olympio, 1954.

SCHWARTZ, S. Escravos, roceiros e rebeldes. São Paulo: EdusC, 2001.

SCHWARTZ, Stuart B. Segredos Internos: engenhos e escravos na sociedade colonial 1550- 1835. SP: Cia. das Letras, 1988

SILVA, Eduardo, REIS João José (orgs.). Negociação e Conflito: a resistência negra no Brasil escravista. São Paulo: Companhia das Letras. 1996.

SILVA, José Bento da. "Cazumbá: História e memória no Recôncavo Baiano(1888-1950)". Anais do XXVI Simpósio Nacional de História - ANPUH • São Paulo, julho 2011.

SILVA, José Bento da. "Cazumbá: História e memória no Recôncavo Baiano (1888-1950"'. Anais do XXVI Simpósio Nacional de História - ANPUH • São Paulo, julho 2011

SLENES, Robert W. "Histórias do cafundó", In. VOGT, Carlos e FRY, Peter, Cafundó - A África no Brasil. São Paulo: Cia das Letras; UNICAMP, 1996 
VALIM, Patrícia. Corporação dos enteados: tensão, contestação e negociação política na Conjuração Baiana de 1798. São Paulo: USP, 2012. (Tese de Doutorado

VANSINA, J. A África Equatorial e Angola: migrações e o surgimento dos primeiros estados. In: História Geral da África IV. África do século XII ao século XVI. SP: Ática UNESCO, 1988. 